\title{
Back to the future of oridonin: again, compound from medicinal herb shows potent antileukemia efficacies in vitro and in vivo
}

\author{
Guang-Biao Zhou ${ }^{1,2}$, Sai-Juan Chen ${ }^{1}$, Zhen-Yi Wang ${ }^{1}$, Zhu Chen ${ }^{1}$ \\ ${ }^{I}$ State Key Laboratory of Medical Genomics and Shanghai Institute of Hematology, Ruijin Hospital Affiliated to Shanghai Jiao Tong \\ University School of Medicine, 197 Ruijin Road II, Shanghai 200025, China, ${ }^{2}$ Guangzhou Institute of Biomedicine and Health, Chi- \\ nese Academy of Sciences, Guangzhou Science Park, Guangzhou 510663, China
}

Cell Research (2007) 17:274-276. doi: 10.1038/cr.2007.21; published online 10 April 2007

Traditional Chinese Medicine (TCM) has been widely and successfully used in treating illnesses ranging from inflammation to cancer, and compounds from medicinal herbs and minerals are playing more and more important roles in taming various kinds of diseases [1], exemplified by artemisinin and arsenic trioxide (ATO). Artemisinin (or Qinghaosu in Chinese) is isolated from a plant called sweet wormwood (Artemisia annua; or Qinghao in Chinese) which has been used as an antipyretic remedy for more than 1500 years in China. Artemisinin has impressive parasiticidal properties in vitro and in vivo, and is now one of the most important class of antimalarial agents [2, 3]. ATO is a common, naturally occurring substance which had been used in China for a long time as a therapeutic agent for some severe diseases with the ancient philosophy of 'treating an evil with a toxic' [4]. In 1990s, ATO was shown to be able to cause partial differentiation at low dose and apoptosis at high concentration of acute promyelocytic leukemia (APL) cells [5], and induce complete remission in $90 \%$ of patients with relapsed or refractory APL [6-8]. These paradigms suggest that TCM is the treasure house not only for the Chinese people, but also for the whole human beings. It is our responsibility to develop evidence-based therapeutic approaches from TCM for diseases with poor prognosis.

Correspondence: Zhu Chen

E-mail: zchen@stn.sh.cn
Isodon plant Rabdosia rubescens which is called Donglingcao in China, is a Chinese medicinal herb used widely in provinces including Henan. The aerial parts of RR and other species of the same genus has been reported to have the functions of clearing "heat" and "toxicity", nourishing "yin", removing "blood stasis", and relieving swelling. RR has been used to treat stomach ache, sore throat and cough. Moreover, RR and its extracts have been shown to be able to suppress disease progress, reduce tumor burden, alleviate syndrome and prolong survival in patients with gastric carcinoma, esophageal, liver and prostate cancers [1]. Interestingly, other Isodon plants including Isodon japonicus Hara (IJ) and I. trichocarpus (IT) are also applied as home remedies for similar disorders in Japan and Korea. These reports suggest that Isodon plants should have at least one essential antitumor component. In 1970s, a bitter tetracycline diterpenoid compound, oridonin, was isolated from RR, IJ, and IT separately, and was shown to be a potent apoptosis inducer in a variety of cancer cells [9-12]. However, whether oridonin can be used in the selected setting of hematology/oncology, and which types of hematologic malignancies could represent the most sensitive ones to oridonin treatment, remain obscure.

The success of using ATO and all-trans retinoic acid (ATRA) in taming APL has been the impetus for us to develop therapeutic approaches for other subtypes of leukemia with poor prognosis. Both ATO and ATRA target the PML-RAR $\alpha$, a fusion protein resulted from $t(15 ; 17)$ chromosomal translocation which plays a critical role in 
APL leukemogenesis [13-15], suggesting that oncoproteins crucial for leukemia pathogenesis could be ideal therapeutic targets. M2 type acute myeloid leukemia (AML-M2) accounts for $25 \%$ of all AML cases, and is characterized by the presence of $\mathrm{t}(8 ; 21)$ chromosomal translocation; and the resultant AML1-ETO (AE) fusion protein is detected in $40 \%$ to $80 \%$ of AML-M 2 patients. AE oncoprotein plays a critical role in $\mathrm{t}(8 ; 21)$ leukemia pathogenesis. Though reports showed that $\mathrm{t}(8 ; 21)$ was a favorable prognostic factor for AML [16], patients with $\mathrm{t}(8 ; 21)$ AML in China and some other countries had a median survival time of less than two years [17]. For these reasons, AML-M2 with $\mathrm{t}(8 ; 21)$ has been a research focus in our institute since 2000, aiming at elucidating leukemogenesis and developing therapeutic approaches.

We investigated the effects of oridonin on a spectrum of leukemic cells including the $\mathrm{t}(8 ; 21)$-harboring Kasumi-1 cell line and primary leukemia cells isolated from patients with de novo or relapsed/refractory $\mathrm{t}(8 ; 21)$ AML. In our work, cell proliferation, cell viability, cell cycle, mitochondrial transmembrane potential, externalization of phosphatidylserine, and in situ cell death were carefully analyzed. We found that among cells tested, $\mathrm{t}(8 ; 21)$-harboring cells were the most sensitive ones to oridonin treatment [18]. Oridonin at clinical available concentrations inhibited growth and induced programmed cell death of $\mathrm{t}(8 ; 21)$ leukemic cells through insult of mitochondria functions and unleash of apoptosis machineries, down-regulation of apoptosis antagonist Bcl-2, and activation of apoptosis executioners including caspase- 9 and -3 . Since AE fusion protein is critical to leukemogenesis, we assessed the impact of oridonin on $\mathrm{AE}$ and found that oridonin treatment could cause a caspase- 3 dependent degradation of AE, and the aspartic acid residue at position 188 of AE (D188) was identified as the cleavage site. The catabolism of AE could lead to reprogramming of its target genes. Intriguingly, in murine models of $\mathrm{t}(8 ; 21) \mathrm{AML}$, oridonin induced apoptosis of leukemic cells and significantly prolonged life span of mice bearing $t(8 ; 21)$ leukemic cells, and inhibited tumor growth in nude mice. These antitumor effects seemed to be superior to that of cytosine arabinoside (Ara-C), because oridonin at 7.5 to $15 \mathrm{mg} / \mathrm{kg}$ per day exerted a more profound antileukemia efficacy than low dose Ara-C, and did not cause suppression of bone marrow or loss of body weight as compared with mice treated with high dose Ara-C. A synergic effect was seen in mice treated with low dose Ara-C and oridonin. These data suggest that oridonin could be effective in treating human $\mathrm{t}(8 ; 21)$ leukemia, and potential clinical trial should be performed to evaluate oridonin as a drug against $\mathrm{t}(8 ; 21)$ AML [18].

More than three decades have passed since the isolation of oridonin from the Chinese medicinal herb RR, but whether oridonin could find clinical application, and which kind of cancer could be the most sensitive one to oridonin treatment, warrant further investigation. Our results clearly demonstrate the potent antileukemia efficacies of oridonin on $\mathrm{t}(8 ; 21) \mathrm{AML}$ with low adverse effect, opening a potential bright future for oridonin treatment which might provide benefits for patients with $\mathrm{t}(8 ; 21)$ AML.

\section{References}

1 Tang W, Eisenbrand G. Chinese drugs of plant origin: chemistry, pharmacology, and use in traditional and modern medicine. Berlin: Springer-Verlag. 1992:817-847.

2 Qinghaosu antimalaria coordinating research group. Antimalaria studies on Qinghaosu. Chin Med J (Engl) 1979; 92:811-816.

3 Woodrow CJ, Haynes RK, Krishna S. Artemisinins. Postgrad Med J 2005; 81:71-78.

4 Li SZ. The compendium of materia medica (Originally published in the Ming Dynasty of China, 1578). Beijing: People's Medical Publishing House. 1982.

5 Chen GQ, Shi XG, Tang W, et al. Use of arsenic trioxide $\left(\mathrm{As}_{2} \mathrm{O}_{3}\right)$ in the treatment of acute promyelocytic leukemia (APL): $\mathrm{I}_{2} \mathrm{As}_{2} \mathrm{O}_{3}$ exerts dose-dependent dual effects on APL cells. Blood 1997; 89:3345-3353.

6 Niu C, Yan H, Yu T, et al. Studies on treatment of acute promyelocytic leukemia with Arsenic Trioxide: remission induction, follow-up, and molecular monitoring in 11 newly diagnosed and 47 relapsed acute promyelocytic leukemia patients. Blood 1999; 94:3315-3324.

7 Shen ZX, Chen GQ, Ni JH, et al. Use of arsenic trioxide $\left(\mathrm{As}_{2} \mathrm{O}_{3}\right)$ in the treatment of acute promyelocytic leukemia (APL): II. Clinical efficacy and pharmacokinetics in relapsed patients. Blood 1997; 89:3354-3360.

8 Sun HD, Ma L, Hu XC, Zhang TD. Ai-Lin I treated 32 cases of acute promyelocytic leukemia. Chin J Integrat Chin West Med 1992; 12:170-171.

9 Fujita E, Fujita T, Katayama H, Shibuya M. Terpenoids. Part XV. Structure and absolute configuration of oridonin isolated from Isodon japonicus trichocarpus. J Chem Soc (Chem Comm) 1970; 21:1674-1681.

10 Henan Medical Institute, Henan Medical College, Yunnan Institute of Botany. Oridonin--a new antitumor subject. Chin Science Bull 1978; 23:53-56.

11 Fujita T, Takeda Y, Sun HD, et al. Cytotoxic and antitumor activities of Rabdosia diterpenoids. Planta Med 1988; 54:414-417.

12 Fujita E, Nagao Y, Node M, et al. Antitumor activity of the Isodon diterpenoids: structural requirements for the activity. Experientia 1976; 32:203-206.

13 Huang ME, Ye YC, Chen SR, et al. Use of all-trans retinoic acid in the treatment of acute promyelocytic leukemia. Blood 1988; 72:567-572.

14 Zhou GB, Chen SJ, Chen Z. Acute promyelocytic leukemia: a model of molecular target based therapy. Hematology 2005; 10 Suppl 1:270-280.

15 Chen GQ, Zhu J, Shi XG, et al. In vitro studies on cellular and molecular mechanisms of arsenic trioxide $\left(\mathrm{As}_{2} \mathrm{O}_{3}\right)$ in the treatment of acute promyelocytic leukemia: $\mathrm{As}_{2} \mathrm{O}_{3}$ induces NB4 cell apoptosis with downregulation of $\mathrm{Bcl}-2$ expression and 
modulation of PML-RAR alpha/PML proteins. Blood 1996; 88:1052-1061.

16 Grimwade D, Walker H, Oliver F, et al. The importance of diagnostic cytogenetics on outcome in AML: analysis of 1,612 patients entered into the MRC AML 10 Trial. The Medical Research Council Adult and Children's Leukaemia Working Parties. Blood 1998; 92:2322-2333.

17 Wang YY, Zhou GB, Yin T, et al. AML1-ETO and C-KIT muta- tion/overexpression in $\mathrm{t}(8 ; 21)$ leukemia: Implication in stepwise leukemogenesis and response to Gleevec. Proc Natl Acad Sci USA 2005; 102:1104-1109.

18 Zhou GB, Kang H, Wang L, et al. Oridonin, a diterpenoid extracted from medicinal herbs, targets AML1-ETO fusion protein and shows potent antitumor activity with low adverse effects on $\mathrm{t}(8 ; 21)$ leukemia in vitro and in vivo. Blood 2006 Dec 29; doi: 10.1182/blood-2006-06-032250 